\title{
From archebiosis to evolution of organisms and informational systems
}

\author{
Yuri Natochin ${ }^{1}$ and Tatiana Chernigovskaya ${ }^{2}$ \\ ${ }^{1}$ Faculty of Medicine, Saint Petersburg State University, \\ Universutetskaya nab., 7-9, Saint Petersburg, 199106, Russian Federation \\ 2Department of the Problems of Convergence in Natural Sciences and Humanities, \\ Laboratory for Cognitive Studies, Faculty of Liberal Arts and Sciences, \\ Saint Petersburg State University, Universitetskaya nab., 7-9, Saint Petersburg, \\ 190000, Russian Federation
}

Address correspondence and requests for materials to Tatiana Chernigovskaya, tatiana.chernigovskaya@gmail.com

\begin{abstract}
Laws of evolution seem to be relevant not only for biological domains, but for informational systems. This paper provides a sketch of a comparison of two systems - that of homeostatic systems, and that of language evolution. We argue that the patterns of evolution of functions are hierarchically organized according to four main levels: I - the primary level: a cell in biology, a phoneme in language; II - functional units: a nephron, a morpheme; III — organs: a kidney (a lung, a heart, etc.), a word; IV - systems: physico-chemical constancy, a sentence or a phrase. There is a set of restrictions for each domain: the linguistic changes have not occurred in all languages, in many cases they are still underway, there are 'old' and 'young' languages, etc. Such comparisons appear to be relevant and can be applied to objects as far removed as these. This allows us to speak of certain evolutionary universals.
\end{abstract}

Keywords: laws of physiological evolution, history of evolutional physiology in Russia, origins of life, language evolution.

\section{Introduction: A glimpse of history}

Citation: Natochin, Y. and

Chernigovskaya, T. 2020. From archebiosis to evolution of organisms and informational systems. Bio. Comm. 65(3): 215-227. https:// doi.org/10.21638/spbu03.2020.301

Authors' information: Yuri Natochin, RAS Academician, Dr. of Sci. in Biology, Professor, Chief Researcher, orcid.org/00000003-2075-5403; Tatiana Chernigovskaya, Dr. of Sci. in Biology, Dr. of Sci. in Philology, Professor, Head of Department, Head of Laboratory, orcid.org/0000-0002-6690-2627

Manuscript Editor: Anton Nizhnikov, Department of Genetics and Biotechnology, Faculty of Biology, Saint Petersburg State University, Saint Petersburg, Russia

Received: April 22, 2020;

Revised: May 16, 2020;

Accepted: May 20, 2020.

Copyright: (c) 2020 Natochin and Chernigovskaya. This is an open-access article distributed under the terms of the License Agreement with Saint Petersburg State University, which permits to the authors unrestricted distribution, and selfarchiving free of charge.

Funding: No funding information provided. Competing interests: The authors have declared that no competing interests exist.
Theories and laws formulated in regards to biological phenomena can impact a greater circle of phenomena. The more objects that comply with the law, the more significance the law has, and it is extended to all new phenomena of the outside world. One of the most significant processes is information transfer, regardless of its recipient. Another highly essential and general factor for the generation and transfer of information is the stability of environments where it is generated, and lowering of the noise level for the signal to be transmitted and received. Formulated differently and using a biological term, it is necessary for the physical and chemical conditions of the environment to be in a stable state - homeostasis. If the principles of system organization are consistent and a researcher understands them correctly, the laws will be applied to correlative objects, regardless of whether they impact complex objects of natural or artificial origin. This article is based on the analysis of the theory of organization of seemingly extremely distant objects - information systems and a key effector organ of the homeostatic system - kidneys.

Problems of evolution initially drew the attention of investigators who studied the emergence and development of life on Earth. History, general questions and principles of evolutionary physiology - covering physicochemical factors in the evolution of functions, the development of organisms' integrity, the origin of physiological adaptation, the development of interconnection of physiological systems, etc - are observed and discussed. 
The term 'evolution' derives from the Latin evolvere, denoting unwinding or unfolding. This word in its modern sense was probably first used by the Swiss naturalist C. Bonnet in 1762. In the 18th and 19th centuries, students of evolution established the foundations of evolutionary morphology. One obstacle in developing such work in physiology must have been the ideas of the comparative anatomist and palaeontologist Cuvier (1769-1832) and other anatomists. Dwelling on the data on the substantial differences in the functions of homologous organs, they came to the conviction that functional research is of little value in solving problems of systematics. But interest in investigating physiological processes increased rapidly: Walter in 1807, Wilbrandt in 1833, and Müller in the 1830s introduced biology to comparative physiological studies. Darwin in his Origin of Species drew attention to the problem of the evolution of structure and function in the organs of animals (1872). From the 1860s through the 1880s, interest in comparative physiological studies greatly increased. Haeckel wrote that the objective of future physiogeny will be an equally exhaustive and successful elaboration of the history of the development of functions as had already long been accomplished in morphogeny with respect to the development of form (1874).

Darwin and physiologists of the second half of the 19th century gave primary importance to the interaction of the organism with its environment, to the influence of environmental conditions, and to the selection of organisms best adapted to external environmental factors. It is worthwhile to recall the work of Bernard, who insisted that two proper milieus exist for animals, including humans: one, the milieu exterieur, in which an organism resides, and the other, the milieu interieur, in which its cell tissues live (1878). The relationship between them is what makes living homeostasis stable.

Attempts were made to clarify not only the morphological, but also the functional principles of the evolution of organisms. Evolutionists pointed out that the development of the evolutionary doctrine was not yet adequately reflected in physiology, in contrast to anatomy. The publication of Lucas on the evolution of functions became an important landmark in the history of evolutionary physiology (1909). The term 'evolutionary physiology' was suggested by Severtsov, who thought that research on the history of physiological functions seemed to present the most difficult aspect of phylogenetic physiological investigation (1914). The new step of evolutionary physiology in Russia was begun by a number of research groups in the 1920s and later (Schmalhausen, 1949), and it is especially associated with the names of L. Orbeli (1941) and H. Smith (1953) in the USA.

On November 16, 1920, Ivan Pavlov addressed the Physico-Mathematical Department of the Russian Academy of Sciences, stating that "during the last dec- ades, physiological exploration has gradually spread over the whole animal kingdom.... Physiology virtually becomes general or comparative physiology". In 1933, Orbeli stressed that the developmental approach is fruitful for both physiological and morphological studies. In 1939 in Koltushi, near Leningrad, Orbeli founded the I. P. Pavlov Institute of Evolutionary Physiology and Pathology of Higher Nervous Activity. Intensive development of evolutionary physiology was also underway in Moscow and Leningrad.

It's important to stress that Leon Orbeli, being a student of Ivan Pavlov, was thinking within a more complex paradigm, which is currently seen as more adequate to the state-of-the-art of this century than the strict reflex paradigm going back to Descartes. Life could not evolve and be stable if organisms were unable to make probabilistic predictions concerning possible events on the basis of previous repeated experience. Even proto-life systems require stability against external perturbations - and it is a prerequisite for evolution.

Such an exceptionally difficult topic as language origins and its evolution from communication signals of other species cannot be avoided by theoretical biologists. Biological foundations and prerequisites for human speech made biologists consider it from an evolutionary perspective. It's hard to imagine that Pavlov's principle of the 'second signalling system' - which distinguishes verbal conditioning, or language acquisition in man from the conditioning of the 'first signalling system' in humans and other animals - could suddenly appear only in a certain species deus ex machina in its fully developed contemporary forms. It is inevitable that there were preliminary stages of development that gradually led to the evolution of modern human language. It's interesting that Pavlov's joint session of the Academy of Sciences and Medical Academy of the USSR caused a dark period in Orbeli's life. One of the 'shortcomings' that he was accused of was an idealistic conception of psychophysical parallelism. His great teacher Pavlov wrote already in 1914 that he totally excludes even a hint of mentioning subjective states in his studies of brain activity. Pavlov was sceptical of Bergson's philosophy, and insisted that all subjective (or phenomenal as we call it now) states are just stories and have nothing to do with science. In fact Pavlov's aim was to substitute 'vague and fuzzy' psychological descriptions of mental states with objective registration of physiological reactions. He could never agree that there is a complex internal world, a 1st person experience, qualia that are either not reflected in physiological activity, or we do not yet know how to juxtapose it.

Still later at 'Pavlov's Wednesdays' he again and again discussed specifics of psychic events. He did not deny animal reasoning and formulated a very strict question - one of the most challenging for physiology: 'How 
can the brain create subjective states?' Pavlov was sure that merging psychic and physiological, subjective and objective, was the most important question for future science. In 1945 Orbeli wrote that the level of scientific expertise had reached the stage when separate study of objective and subjective worlds is irrelevant, and physiologists have to include the latter to their paradigms; he insisted that only the parallel study of both could give us an adequate picture of human higher nervous activity. He also promoted the use of ontogenetic, phylogenetic, and pathological data (including recapitulation) to reveal evolutionary features.

Amazingly, these battles are still active in another domain. Compare nativists' views with those of functionalists on language origins and its specific features and the seemingly never-ending discussions of phenomenal mind and qualia (Pinker, 1994; Chomsky, 2000; Deacon, 2003, 2004, 2013; Jackendoff, 2003-2004; Chernigovskaya, 2004, 2007, 2013; Friederici, 2011, 2017; Chomsky and McGilvray, 2012; Slioussar et al., 2014; Kireev et al., 2015). So the debate continues in spite of all the new methods and technologies that have become available to explore these questions. Inborn preference of human infants to perceive human faces and speech sounds have obvious parallels with ecologically based inborn preferences in other species. It is important to stress that such capacities need to be fine-tuned by the external world because their genetic basis only subserves potential abilities. Thus, universal grammar in humans requires that its parameters are formed by a specific language surrounding. The approach of phylogenetic development considers that individual ontogenesis plays the leading and primary role in evolution, and considers the unfolding of more stable and long-term patterns (reflexes) to be a product of individual associations in learning during the lifespan.

Today, evolutionary ideas in the domain of cognitive research are becoming increasingly influential and promising. For example, the complex multilevel conception of the evolutionary process developed by Terrence Deacon (e.g., in his book Incomplete Nature. How Mind Emerged from Matter (2013)) treats mental processes in general and human language in particular as spontaneously evolved emergent adaptations that are quite unlike formal computational systems. In this view language structure is the result of self-organization and selection processes interacting across genetic, physiological, and social levels and reflects the converging influences of semiotic constraints, neural processing limitations, and social transmission dynamics. From this multilevel perspective, the biological basis of this unprecedented adaptation is not located in some unique neurological structure, nor is it the result of any single extraordinary mutation, but rather it is a result of the interaction of these coupled evolutionary dynamics.
The prescient ideas of Orbeli and his followers continue to be relevant for formulating general principles of evolution, not only in biological but also in symbolic informational systems. They foresaw the development of a convergent science, aiming to merge not only different domains, but science and arts per se (Lehrer, 2007; Pribram, 2013). Some examples of this convergence will be discussed below.

\section{Methods of evolutionary physiology}

It is essential to study phylogenetic aspects of evolution of functions by the methods of comparative physiology, and to elucidate the establishment of functions in the course of individual development both in pre- and postnatal ontogenesis. Clinical studies are also very important, since certain disease symptoms may reflect what occurred at earlier stages of development. Thus, functions in pathology can be considered as a kind of a return to earlier developmental stages of functions. Another method of evolutionary physiology draws on comparisons of possibilities of adaptation of animals and man at different stages of individual development in a wide variety of environments. The study of functions under extreme environmental conditions or in the presence of unusual factors in the $m i$ lieu exterieur can reveal functional reserves and the range of evolutionary plasticity. Finally, substantial information on evolutionary physiology may be obtained by pharmacological and toxicological studies (Natochin and Braunlich, 1991), as the differential sensitivity to the effects of toxic substances seen in different classes of animals can be found also in the early stages of postnatal ontogenesis, particularly in birds and mammals. This makes it possible to analyse such phenomena as resistance, functional states of cellular metabolic systems, and their plasticity. All of these approaches of evolutionary physiology necessarily involve physiological, biochemical, biophysical, molecular biological, and morphological methods, as well as the methods of mathematical modelling and genetics.

\section{Language evolution}

In the past decades there has been increasing progress in the development of the multidisciplinary domain of language origin and evolution. This progress has resulted from paradigms and data being shared between researchers who study such subjects as disparate as historical linguistics and archeology on the one hand, and primatology, anthropology, anatomy and neurosciences on the other (Bunak, 1980; Fitch, 2000; Bolhuis and Everaert, 2013; Cartmill et al., 2014). There is a wealth of findings indicating not only that cross-disciplinary borrowing of data provides further knowledge, but also that theoretical implications and analogies prove valuable and productive. 
The contribution of paleo-anthropological research to the problem of language evolution is well acknowledged. Most relevant for the purposes of this paper are studies that further support the possibility of establishing a relationship between linguistic typology or differentiation and evolutionary affinities (cf. Falk, 1987; Cavalli-Sforza, Piazza, Menozzi and Mountain, 1988; Delson et al., 1991; Ragir, 1992; Wind et al., 1992; Cavalli-Sforza, Cavalli-Sforza, Menozzi and Piazza, 1994; Wallace, 1994; Read, 2008; Sia, Clem and Huganir, 2013). For example, Cavalli-Storza et al. (1988, 1994) demonstrate a congruence between genetic and linguistic evolution in human populations. They conclude that linguistic and genetic evolution are closely related and that associations between linguistic families and the genetic history of humans is far from random. Reformulating Darwin's prediction (Ch. 14 in Origin of Species (Darwin, 1872)) that information on the genealogical arrangement of man would enable classification of languages currently spoken, they indicate that when general principles of correlation between the genetic tree and linguistic families and super-families are established, predictions can be made on the time course - and even locations - of the origins of linguistic families. It is evident that the 'realization' of human language is achieved through articulation, audition, and mental processing (Allott, 1980, 2001). Therefore, evolution is seen in peripheral-articulatory, auditory, and integrative systems of the brain. The latter, however, are a subject of constant controversy compared to the former two. While behaviorists and some artificial intelligence researchers treat the brain as a general purpose processor, Chomsky's followers describe it as a bundle of highly specialized 'instincts' ('universal grammar' among them) designed by evolution to learn certain things (Donald, 1993; Sia, Clem and Huganir, 2013). Discussions over this dichotomy never end.

This congruence prompts us to ask: What about linguistic evolution as compared to biological evolution? Are these processes subject to similar causal principles? Of course, the rate of language change is much faster than that of biological change. Nevertheless, at least some traits seem to be comparable.

Many theorists have argued that the principles reflected in organic evolution go far beyond the province of biology alone, and appear to have a general nature (from Karl Popper to Donald Campbell, to David Hull, to Daniel Dennett, to Terrence Deacon, etc.). In the present paper, concerned with supporting the above view, two different subjects of study have been chosen: the systemic organization of natural language and of organism physiology. The physiological system maintains the constancy of the physicochemical parameters of the internal milieu in the body, preserving conditions for the affective function of the brain and sensory or- gans, but depending itself on the brain's coordinating activity. A natural language also maintains a complex interdependent set of relations among its components despite being distributed among thousands or millions of users extending across centuries, who each acquired this complex system in diverse independent developmental contexts. Both are products of a long period of evolution.

\section{Homeostatic systems and principles of evolution}

Brain-controlled homeostatic systems do their best to provide a high degree of constancy of the milieu internal in the face of wide fluctuations in the milieu external. Almost six decades after C.Bernard's introduction of the concept, J. Barcroft wrote that over the ages, the constancy of the internal medium has become increasingly accurately regulated until, in the long run, it reached a degree of sophistication which enabled the development of human capabilities (934). Thus, man could come to cognize the world around him in terms of abstract knowledge. Barcroft gave a graphic answer to the question why the physicochemical parameters of the milieu internal are required to have the highest degree of stability. He wrote that the chemical and physiological processes associated with mental activity are so delicate by nature that in comparison, changes measured with a 'thermometer' or a 'hydrogen electrode' look enormous, and potentially catastrophic. To presume high intellectual maturity in conditions of unstable milieu internal properties is like listening to music in the crackling of an ill-tuned broadcast, or observing a ripple left by a boat on the surface of an Atlantic Ocean storm.

Thus, it can be inferred that progressive development of higher cortical functions, including informational systems, requires an internal milieu which is as stable as possible. This idea was expressed aphoristically by C. Bernard as: "La fixité du milieu intérieur est la condition de la vie libre" (1878). The importance of a stable internal milieu is well exemplified by renal function in higher animals. The kidney plays a key role in the maintenance of the physicochemical constants of the internal medium, such as the volume of extracellular fluids, their chemical composition, osmolality, and $\mathrm{pH}$.

Darwin and his various followers, including Haeckel, Lucas, and Orbeli, were primarily interested in the origin and evolution of functions. Between 1875 and 1886, the principles of functional change in the evolution of organs and the principle of organs' substitution were formulated. And by the beginning of the $20^{\text {th }}$ century, A.N. Severtsov proposed the principle of the intensification of functions in evolution and the multifunctional nature of organs (1914). These concepts were built largely on morphological grounds, but from the physiological 
point of view it is obvious that each organ can perform its functions only as a part of whole functional systems. For this reason it was thought that the principles of evolution of functions in physiological systems should be considered with respect to the different levels of their organization (Natochin, 1987).

In the case of a homeostatic system, particularly that of water-salt homeostasis, we can distinguish the evolution of functions into four levels. On a primary level we consider specialized renal cells (I). The next level corresponds to the evolution of functions in the nephron (II), which is the basic functional unit of the kidney; the third level is the evolution of the whole organ (III), that is, the kidney itself. The yet higher level involves the evolution of the larger physiological system (IV) that kidney function contributes to, i.e., ionic homeostasis within the organism. Regulation of the watersalt balance includes specific receptors (osmo-receptors, volume receptors, ion receptors), central nervous system integrative centres, efferent nerve outputs, as well as humoral regulatory factors (hormones, autacoids, etc.) and other effector organs besides kidneys (e.g., salt glands, gills, etc.) that are collectively regulated by the hypothalamus of the nervous system.

\section{Language and principles of evolution}

A similar four-level approach may be applied to natural languages. Although evolutionary ideas in linguistics are still not well recognized, even in the 19th century, when language first came under the scrutiny of systematic science, a few successful attempts were made to apply evolutionary ideas from biology to the description of language (e.g., Humbolt, 1936; Schleicher, 1873). Although related attempts were made by such prominent linguists as Sapir (1921) and Jespersen (1964), they were not taken seriously until recently. This is because in the 20th century, through the influence of Saussure (1916), Jakobson (1966), and others, up to Berwick and Chomsky (2015), language came to be viewed as a static system with a set of rules for the combination and substitution of elements, regardless of how it may have evolved from protolanguages to modern languages. Thus, the idea that language could be studied from an evolutionary perspective - i.e., that human languages evolve and become adapted to their uses and users' capacities (e.g., Deacon, 2013) - was largely ignored within linguistics, despite the fact that it is a biologically evolved phenomenon.

Nevertheless, since the beginning of comparative linguistics and throughout its subsequent extensive development in the 20th century, there has been much discussion on the issue of language typology - comparing both related and widely separated languages and also on the question of what features may be shared by all languages. Studies attempting to reconstruct ancestral protolanguages made significant strides during the latter decades of the $20^{\text {th }}$ century (cf. Gamkrelidze and Ivanov, 1985). General features of language evolution were first identified in the family of Indo-European languages, because they were the most extensively studied and their forms could be traced for six to seven thousand years. Regularities revealed in the studies of Indo-European languages have turned out to be applicable to the evolution of other language groups as well: Afro-Asian, Altaic, Uralic, and others. Thus, there appear to be regularities of evolution which are widely shared among different languages, and which can be traced at different levels, from that of phonology (I) up to the sentence level (IV).

It is important to bear in mind that these regularities will be expressed differently, according to the type of language being considered. For example, in tonal languages changes can take place almost only in tones. In languages of other phonological types changes may occur in the segmental sounds or phonemes. Furthermore, linguistic features are 'scattered' over different languages and are not necessarily present in each of them.

Despite the extensive differences distinguishing languages and organisms, the evolution of language characterizing comparable, though differently expressed phenomena - can be traced over time in ways that are similar to the tracing of structural-functional changes in the evolution of organisms. Thus, an interdisciplinary analysis of the data of historical linguistics on the one hand, and ontogenetic data on first language acquisition on the other, may shed light on general principles common to both domains.

Efforts to simulate the functions of fossil anthropoid species' sound-producing apparatus and the sounds that could be articulated by this apparatus provides one realm of methodological overlap, as are efforts to reconstruct the cognitive capacities of our hominid ancestors based on neurological predictions and extrapolations from comparative data. Valuable information on this topic is to be found in the studies of linguistic functions as related to cerebral mechanisms (Bichakjian, 1991; Chernigovskaya, 1994; Gor and Chernigovskaya, 2004; Lieberman, 2013).

In recent years, attempts have been made to discuss language development in terms of processes recognized in biological evolution, such as paedomorphism, neoteny, recapitulation, language hybridization, monoand polygenesis, etc. Substantial contributions to this have been made by Bichakjian (1991). In this paper, we will only consider data on the evolution of the best-studied Indo-European languages to exemplify the principles of functional evolution inherent to all four levels of hierarchical organization exemplified in both biological and linguistic systems. 


\section{Principles of evolution of functions}

\section{Primary element (I)}

\section{EVOLUTION OF PHYSIOLOGICAL FUNCTIONS AT THE CELLULAR LEVEL}

To realize homeostatic activity in a system it is necessary to develop specialized subsystems for the excretion and secretion of substances. Excretory organs in the metazoa may consist of different parts that reabsorb filtered substances from blood and return them to blood, and synthesize new compounds necessary for more effective removal of substances from the body. The kidney participates in performing many additional functions including the incretory and endocrine ones. For these functions to be realized, directional transport of substances is required (reabsorption - from the tubule lumen to the blood by the tubular cell or secretion from the blood to tubular lumen (urine) by the tubular cell). The primary event in the origin of the excretory organ was the specialization of initial ('ancestral') forms, resulting from the emergence of an asymmetric cell capable of directly transporting substances. This process involved the functional biochemical differentiation of the opposite sides of the cell - the apical and basal plasma membranes, with the allocation of ion channels principally to the former, while allocating ion pumps, hormone and transmitter receptors to the latter side, as well as the redistribution of mitochondria throughout the cell. Thus, the evolution of the excretory organ cell has its origin in the formation of an asymmetrical cell through cellular specialization.

The basis for the evolution of kidney function in vertebrates lies in increasing energy metabolism and energy consumption - especially in warm-blooded animals, in contrast to cold-blooded ones. This process is reflected in the intensification of trans-cellular transport of substances, the increase in oxygen consumption and numbers of mitochondria, and the increase in oxidative enzyme activities. All of the events represent another important principle of evolution - the principle of intensification of cellular function.

The comparison of cells from homologous parts of nephrons in representatives of various classes of vertebrates (from hagfish to mammals) that took hundreds of millions of years to evolve reveals an increase in the number of cell types that differ morphologically and functionally from each other. In other words, the evolution of function is related to the differentiation of nephron cells. This may be the result of a simplification or complication of certain cellular functions, or only an increase (or loss) of distinct forms of initial cellular activity.

The evolution of cellular function is accompanied by an increase in the cell's ability to perceive and respond to outside stimuli, and to more accurately fulfil its func- tions in the whole organism. This is reflected in an increasing number of specific receptors of various kinds for different hormones, autacoids and transmitters, and in the realization of cellular responses together with different intracellular signalling systems. The increasing efficacy of cellular function - and the evolution of functional systems - depends not only on the effects of distant regulators (hormones, transmitters), but also on the intercellular interactions accompanied by the specialization of cell-to-cell junctional complexes.

\section{EVOLUTION OF PHONEME FUNCTION}

In this part of the paper we try to analyse linguistic data to show similarities and differences in the evolution of phonemes as compared to the evolution of the first level of the physiological system - the cell.

The phoneme is the minimal sound unit of language, enabling us to distinguish the meanings of different words and morphemes. The sound system of protolanguage most likely comprised very few vowels. The most frequent one was the sound /e/, less frequent was $/ a /$, still less frequent were $/ \mathrm{i} /$ and $/ u /$. There existed laryngeal $h$-like sounds which later dropped out (an example of a decrease in the number of similar units sound regression, phoneme regression). Language development led to an increase in the number of vowels $/ i /$, $/ e /, / a /, / o /$, and $/ u /$ (grouped in two subclasses of long and short vowels (increase in quantity and change of quality)). Different articulation variants of the same cardinal (basic) set of vowels, as they are generally called, subsequently arise with a tendency toward increasing differentiation: nasal, mid-, front-, etc.

The same trend is evident in the neglect of 'complex', 'mixed' sounds, the tendency towards the formation of 'simple', more clearly articulated sounds, and the elimination of co-articulations. This can be readily illustrated by the example of consonants which evolved from complex mixed sounds to a variety of separate sounds covering the full range of possible articulations, from $\mathrm{s}$ to ps to fricatives.

Undoubtedly, these events reflect an increase in the intensification of phoneme function, a specialization of contact types, and an increase in the number of modes of functioning. This is expressed in the possibility of combining certain sounds, while other combinations are impossible, as most clearly seen in comparing different languages. Vowel changes have resulted in changes in the quality of adjacent consonants, e.g., in making them voiced or voiceless. The process of such changes can be exemplified by the merging of the Indo-European sounds $/ e /, / 0 /, / a /$ of different timbres into the Sanskrit $/ a /$.

Regression shows itself in the disappearance of glottalization and in the degradation or substitution 
of aspiration in other sounds, e.g., aspirated fricatives Noteworthy is the division of the 'double' sound into two different classes, e.g., labio-velar sounds disappear in the course of evolution, being substituted by labials and velars.

The same type of new sounds can have different origins, e.g., voiceless aspirate consonants in Sanskrit can stem from either voiceless non-aspirate sounds plus ' $h$ ', or from voiced aspirate consonants. The long vowel in Sanskrit came from the Indo-European short consonant plus $/ h /$ (an example of the substitution of function). Thus, the general tendency in the development of speech sounds in our examples is towards higher phoneme differentiation.

\section{Functional units of an organ (II)}

\section{EVOLUTION OF NEPHRON FUNCTION}

The nephron is the main morpho-functional unit of the kidney. Each human kidney has about one million nephrons. This, however, does not imply that all of them are uniform. In mammalian kidneys there are up to eight distinct nephron populations (superficial, intra-cortical, juxtamedullary). The increase of nephron heterogeneity may be regarded as one of the features of evolution in functional units. The kidneys of lower vertebrates do not have such a variety of nephrons, and lack a number of functions that originated later in the kidneys of mammals and birds.

Increased differentiation of nephrons is characteristic of mammals and birds compared to lower vertebrates. Kidney efficiency is characterized by the degree of constancy in the composition and volume of body fluids.

Another feature in the evolution of nephron functions is the intensification of reabsorption and secretion in warm-blooded vertebrates as compared to cold-blooded ones. This is due to the intensification of cellular activity and the reorganization of cell-to-cell junctional complexes in different parts of the nephron, both of which form preconditions for absorption of greater amounts of various organic and inorganic substances and water.

In kidney evolution, the formation of new morpho-functional complexes takes place, and the complex (medulla) includes the vasa recta and the loops of Henle in warm-blooded vertebrates. In the former case, it's a prerequisite for the appearance of a structure that analyses information on tubule content. In the latter case, these elements make up a system that contributes to the formation of a new kidney function related to osmotic urine concentration.

The increase of nephron heterogeneity and differentiation, the intensification of basic nephron functions, the formation of complexes with tubule vessels and interstitial cells with intercellular matter - all these factors raise the regulation of renal functions to a quantitatively higher level, and thereby ensure more efficient maintenance of the physicochemical constancy of the internal milieu. Thereby mammals, as compared to lower vertebrates, obtain new homeostatic possibilities due to their enhanced ability of regulating kidney functional activity.

\section{EVOLUTION OF MORPHEME FUNCTION}

In linguistics, the minimal meaningful segment is a morpheme. There are several types of morphemes: root, affixal, suffixal, derivational (word-formative), etc. Language structure has undergone a number of successive changes in its development from protolanguage to its modern forms. This pertains both to changes in grammatical features and how they are marked.

Increased differentiation appears in the progressive separation of elements' roles: i.e., inflexions become particles with specific fragmentary meanings. A narrowing of functions also occurs, as morphemes previously incorporated into words become separate units - words with distinct grammatical functions; and as the ancestral absolute (indefinite) case splits up into different cases.

A reduction or complete regression of functions is observed in, e.g., the decreasing number of categories (for numbers and genders - from 3 to 2); a complete elimination of cases is possible; and a trend of abandoning declension is observed.

These processes are compensated by intensification (increase), the development of preposition roles, the appearance of articles, and a shift towards a more economical algorithm - from synthetic to more analytical forms. This is achieved by strengthening regulation, particularly by the introduction of a syntactically relevant order of elements, their stricter agreement in a system. As a result, the formation of 'morpho-functional complexes' (analogous to those described above for biological objects) takes place, which provide for new functions by merging two or more forms with different meanings.

We can see an increase in the number of same-class units, each of them with a different meaning (e.g., prepositions), and the emergence of a new class (articles); these are required to provide a new function - analyticity, leading to more flexible syntax. A change of morpheme functions becomes apparent in the emergence of new qualities in already existing units, with possible regression of earlier ones: the future tense and the subjunctive mood originated from three archaic aspectual forms (aspects), which took place after the common Indo-European protolanguage split. This can be exemplified by the conversion of aspectual and modal forms into temporal ones: the three aspectual forms (Present, 
Aorist, Perfect) of Indo-European language become two tenses (Present, Preterite) and two moods (imperative and indicative) in Anatolic languages. The Perfect aspect turns into a temporal form, and the Objective Future Tense is formed from the subjective modality.

In general, there is a narrowing in an element's role from a poly-function alone towards more specialized ones, with vector to fragmentary, independent expression of one or another function. As an example, a tendency can be traced of shifting from the 'heavy' synthetic forms, peculiar, as an example, to Russian syntax, to the 'light' analytical constructions of the English type. We can also observe increasing heterogeneity when an element's polysemy may result from its position in the whole structure.

\section{An organ (III)}

\section{EVOLUTION OF KIDNEY FUNCTION}

Obviously, there is no need to develop an argument for the interrelationship between structure and function, particularly when this concerns the principles of evolution of organ functions. At the same time, some of these principles reflect to a greater extent the evolution of organ structure, while others, on the contrary, account better for the evolution of organ functions (e.g., increase in the number of functions). It is worthwhile to bring together the principles of morpho-functional evolution because they provide a deeper insight into the principles of development of both structure and function of the physiological systems being investigated.

Increased multi-functionality can be seen as a characteristic feature of organ evolution. The kidneys of lower vertebrates provide fluid volume and ion regulation. In the lamprey, the possibility of adapting to fresh water depended on the appearance of a new kidney function - hyperosmotic regulation. In vertebrates the kidneys, in addition to excretion, produce a number of hormones and autacoids that participate in the regulation of mineral metabolism, arterial pressure, and perform some other functions.

Glomerular filtration rate and reabsorption of substances are 10-100 times greater in mammals than in lower vertebrates, as calculated per $1 \mathrm{~g}$ of kidney weight. This points to the intensification of processes responsible for kidney functions activity as one of the main lines in the evolution of renal function, as relative kidney weight in relation to body surface does not increase during vertebrate evolution.

A qualitatively new factor in the evolution of renal function in birds and mammals was the appearance of the ability to regulate osmotic homeostasis under conditions of water deficiency, and to survive for a long time in the desert without any water. Development of this new function was determined by the formation of two layers in the kidney - the cortex and medulla. The principle of 'superstructures' may be regarded as one of the fundamental principles of the evolution of organ functions, including that of the kidney.

A change of functions is another essential principle in the evolution of functions. For example, the kidneys of teleosts have functions (i.e., blood cell production) that in higher vertebrates are lost, although higher vertebrate kidneys still participate in the regulation of blood cell production (erythropoietin).

The principle of substitution of an organ or its functions can be illustrated for kidneys by several examples. In bony fishes, ion excretion occurs not only in kidneys but also in gills. Salt glands bear the main burden of hyposmotic regulation in many species, and kidneys become the main organ of osmoregulation only in mammals.

Decrease in the number of similar organs and increase in the number of morpho functional units are significant factors for the growing role of the kidney as a principal homeostatic organ. The numerous, metamerically arranged metanephridia in earthworms give way to paired excretory organs in molluscs, crustacea, and vertebrates. In the paired organs, e.g., in the kidneys, there are numerous functional units: nephrons (about $1 \mathrm{mln}$. in each kidney in man).

The principles of evolution of functions characterizing progressive kidney evolution, such as multi-functionality, intensification of functions, etc., have been dealt with above. However, development may be accompanied also by regression of at least some functions. This may be illustrated by the loss of the ability to produce hyposmotic urine in marine bony fishes, as compared with their ancestors the freshwater fish, and by a reduction of the number of glomeruli and glomerular filtration rate, which decrease water loss in kidneys.

The regression of renal function may be illustrated on the water vole (water rat), who lost both the ability to osmotically concentrate urine and, therefore, osmoregulation capacity in conditions of water deficiency. The second migration of bony fishes from river to seawater hundreds of millions of years ago led to irreversible changes in a number of systems, including the kidney, which resulted eventually in the loss of hyperosmotic regulation - the ability to excrete hypo-osmotic urine, excrete solute-free water, and to live in fresh water. In anadromic migration of monocyclic salmon, soon after the fish enter the river from the sea, they are unable to return to the sea due to a functional switching in the osmo-regulatory system and an irreversible loss of the physiological mechanisms of hyposmotic regulation of 'producing' fresh water in the sea to keep water balance. Only some fishes could adapt to living both in fresh and marine water. 


\section{EVOLUTION OF WORD FUNCTION}

Language development shows an increase in the number of morphemes in a word, resulting in a decrease in the number of words. Earlier existing morphemes are used for coining new words in modern language. These are: archi-, anti-, poly-, etc. Word groups are formed according the principle of supra-structure: coordinative 'bread and butter', subordinative - 'fresh milk', constructions - 'I saw him coming'.

In Indo-European protolanguage, words in the sentence did not subordinate but adjoined each other as if they were on their own. Later on, they began to be united into groups, with the form of one word beginning to affect the form of the other (Bichakjian, 1991); however, this was not yet a sentence. Change of function reveals itself in that pronouns start playing the role of conjunctions. Combining cognitively dissimilar phenomena into a new single linguistic unit takes place.

Differentiation of word function is apparent in that particular meanings evolve from more amorphous ones; differentiation of the cognitive and grammatical roles takes place - separation of subject and object, agent and patient, etc. The tendency towards regulation, fixed word order in the sentence, and constructions is a significant feature of the evolution of this linguistic level. On the other hand, increase of multi-functionality manifests in the appearance of dissimilar, sometimes very different meanings in the same word.

Regression of functions, including irreversible ones, can be seen in the disappearance, dropping out of words or some of their meanings (archaisms). One is justified in speaking about valences, i.e., the ability of words to combine with each other, as both strongly varying in different languages and also being their universal characteristics.

\section{System (IV)}

\section{EVOLUTION OF THE WATER-SALT BALANCE SYSTEM}

The system of water-salt balance governs the stability of physicochemical parameters in animals and humans, including fluid volume in the body, osmolality, $\mathrm{pH}$, ions and concentration of blood plasma, extracellular fluids. The investigation of organisms belonging to different types of Proto- and Deuterostomia, and different classes of vertebrates at different stages of postnatal development points to the following principles as most significant in the evolution of functions of the system: (1) increase in the number of regulatory factors (2) increase in the number of regulated parameters, and (3) increase in the precision of homeostatic control.

In most marine invertebrates and hagfish, the regulated parameters of the internal milieu also include $\mathrm{pH}$ and concentration of certain ions. Lamprey, fish, and other higher vertebrates have systems to stabilize blood and body fluid osmolality (osmotic pressure). This opened up new avenues for these animals to occupy seawater, freshwater, and terrestrial areas. A comparison of the functional organisation of systems regulating water-salt balance in animals at different levels of development indicates that a number of humoral regulatory factors change. Thus, for each of the ions of particular significance for cellular activity, there are not one but two and even more hormones and other regulatory factors. In the present paper, where special attention is focused on informational systems, it is important to point out that both regulatory peptides, various hormones, autacoids and incretins may be considered as 'words' of the biological language of homeostatic systems.

An increase in the number and role of regulatory factors is not the only mechanism employed in evolution to attain higher quality of regulation. Our studies on the impact of the nervous system on muscles show that while the stimulation of one group of nerves may have a triggering effect, the stimulation of another one exerts adaptive control by adjusting the muscle to its immediate demands. With specific hormones, particularly vasopressin, two types of effects are established. One of them, produced when V2 receptors are stimulated by vasopressin, induces an increased water permeability in the epithelium of some osmoregulatory organs; the other one depends on the stimulation of V1 receptors in the same cell. In the latter event, the release of other second messengers and the modulation of permeability level take place, there by changing the intensity of water transport. As a result, greater precision is attained in the regulation of blood osmolality, which is of prime importance for cellular activity in many systems - especially the nervous system, including higher cortical functions and the state of cognitive functioning. Cell volume fluctuations depend on changes in extracellular fluid osmolality. This parameter must be maintained with utmost precision for cellular functions to be efficiently performed. During vertebrate evolution, there is an increase in the homeostatic ability of kidneys with respect to various physicochemical parameters of the internal milieu, as well as with respect to other effector organs and systems.

\section{EVOLUTION OF SENTENCE FUNCTIONS}

In as much as sentences are formed of words according to certain rules - which are both universal, reflecting general cognitive characteristics of humans, and specific, inherent to particular languages - one cannot but touch upon the evolution of such rules themselves (i.e., syntax) when considering this level. In this respect, a number of general trends should be emphasized. 
First of all, linguists analyse the following tendencies in the evolution of syntax: cognitive aspects, such as role definition - action, agent, object of action, etc. - on the one hand, and proper linguistic aspects on the other: the appearance of such sentence parts as the subject, predicate, and object, not necessarily coinciding with cognitive roles. This divergence indicates an increase in functional specialization.

We can also see a reorganization of sentence structure aimed at increasing its functional adequacy - the ability to express complex systems of notions and relations. The structural hierarchy reveals itself in the emergence of subordination - first, in word groups within a simple sentence, and then in the formation of specialized subordinate clauses.

In syntax, we can note an increase in the degrees of syntactical freedom - a shift to more mobile rules applied to both separate sentence parts and separate sentences within complex sentences, the substitution of the declension system for syntactical functions (which represents a more economical algorithm), and, accordingly, the introduction of syntactically more relevant word order.

The trend of syntax evolution can be tentatively presented as follows: from groups of equivalent words to correlated ones, and from the combination of two simple equivalent sentences - patterned as to correlate the origin of the subordination within the sentences to the origin of complex sentences. Development proceeds towards the emergence of complex sentences with subordination and coordination at different levels (e.g., one inside the other). Various participial and other constructions can be included here, too. The concept of syntax depth (i.e., of coordination and subordination levels) has been developed to describe these extremely complicated constructions. Language historians point to the interesting phenomenon of 'reversion' of grammatical structure in the process of language evolution: from the 'object-action' type to the 'action-object' type, and from the 'left-branching' structure to the 'right-branching' one.

\section{Discussion}

Evolution manifests itself in versatile living forms. Developments in genetics and molecular and system biology have led to intense progress in evolutionary theory. The evolution of life has progressed in continuous interaction with the environment, between inorganic and organic domains. There is no doubt that the fundamental features of inorganic chemical elements predetermined their role in forming the foundations and conditions for the basic organic components of life and living beings. We presume that the genesis of proto-cells created the first whole functional structure adaptable to the milieu exterieur, and able to prevail in the natural selection of the most adapted species in a changing environment. Life and development in a changing world gain enormous advantages from the use of information. This indicates that development has been subserved by a constant interaction between living systems of different levels of complexity and relevant informational systems.

The key point here is answering the question about the first stage of a living object (Noble and Boyd, 1993). As it is a cell, and not its elements, that gives adaptable progeny, we assume that a proto-cell was a first-stage living being that had to be self-sufficient, independent, and protected by a membrane. In the huge diversity of living cells $\mathrm{K}$ ions dominate intra-cellularily, while the extracellular fluid is dominated by $\mathrm{Na}$ ions. Therefore, theoretically it does not seem possible to create the first K-rich cell in a Na world (ocean): a Na pump is needed. Protein synthesis requires the predominance of $\mathrm{K}$ ions. After the emergence of plasmatic membrane, adaptation to various external circumstances becomes possible. This leads us to argue that archebiosis did not begin in a sea rich in sodium (as was accepted earlier), but in lakes where $\mathrm{K}$ ions are predominant (Natochin, 2010). This is supported by geochemical data (Galimov, Ryzhenko and Cherkasova, 2011; Galimov, Natochin, Ryzhenko and Cherkasova, 2012). Another idea is developed of archebiosis in geothermal fields (Mulkidjanian et al., 2012). The listed environments provide conditions for effective protein synthesis and the formation of a minimal set of components necessary for functioning in cells that were already surrounded by plasmatic membrane, ensuring their independence and adaptability.

The following two steps were of extreme importance: the emergence of multi-cellular organization and differentiation of functions (circulation, digestion, respiration, and excretion) (Natochin, 2012), as well as the informational system subserving both intra- and extracellular signalling and interaction (Natochin, 2009). Difference in the size and some other parameters of $\mathrm{Na}$ and $\mathrm{K}$ ions is very small, while the concentration of $\mathrm{K}$ ions within a cell is ten times higher. Our research provides an understanding of the physicochemical nature of this (Natochin, 2012; Dubina et al., 2013; Dubrovskii et al., 2013).

There is a growing interest in bio-evolutionary perspectives on the mechanisms that underlie the complexity of human behaviour and language evolution (cf. Natochin and Chernigovskaya, 1997; Givón and Malle, 2002; Hauser, Chomsky and Fitch, 2002; Dahl, 2009; Cartmill et al., 2014). The main features outlined are graduality, structural differentiation, and adaptivity. Mayr stresses that 'the evolutionary changes that result from adaptive shifts...are followed secondarily by a change in structure' (Mayr, 1976), and that 'during a succession of functions a structure always passes through a stage when it 
can simultaneously perform both jobs' (Mayr, 1976). Givón formulates six general principles that in his view control both language and biological evolution (Givón, 2009): graduality of change; adaptive-selection motivation; functional change and ambiguity before structural change and specialization; terminal addition of new structures to older ones; local causation with global consequences, and uni-directionality of change.

\section{Conclusion}

Life development was based on physical and chemical limitations. If we assume that one of the purposes of the development of the universe was life - then creating a living cell in an inorganic world on one of the planets was a kind of anticipation at one of the stages of evolution. Then a crucial question arises - what is it that distinguishes living and inorganic nature? One should not get attached to trivial topics like carbon, genes and proteins but better think what concrete elements of inorganic nature become constitutive and integral components of the living. Those are the same in a proto-cell as well as in the ocean and in a geological mineral, and in any cell of living creatures - from amoeba and infusoria to monkeys and humans.

At the same time, in all the diversity of living forms and their cells - be it a neuron or a nephron $-\mathrm{K}$ ions dominate in the cytoplasm while $\mathrm{Na}$ ions dominate in extracellular fluid. This can be seen as the main point of nature at the start of life that remained intact through innumerable generations. As it was discussed earlier, these cations have no difference in electric charge, and their sizes differ insignificantly. However, the difference between the ion concentration in the cytoplasm and the pericellular liquid is 10 times or more. Concentration gradient between a cell and the extracellular fluid provides for electro-genesis as the basis for information transfer. The reason, rather, was that $\mathrm{K}$ ions are specifically good for protein synthesis, which made them be successfully used in the proto-cells and living systems, while electro-genesis, which at the beginning was just a side effect, was later used as a precious advantage.

The discovery of such an anticipatory choice of nature can be seen as a kind of intuitive insight per se. It was a sudden understanding that the hypothesis of archebiosis from a sodium ocean medium is irrelevant, as it is impossible to create a $\mathrm{K}$ cytoplasm there (Natochin, 2005), so another idea appeared based on initial K water basins (Natochin, 2010), that was confirmed by geochemical data (Galimov, Natochin, Ryzhenko and Cherkasova, 2012) and in a special experiment (Dubina et al., 2013). A proto-cell could then accommodate to salt and fresh water, evolve to higher forms of life reaching conscious mind, intuition and different forms of information processing.
This paper has attempted to substantiate the applicability of some principles of evolution of functions to phenomena as different as those of natural language and a physiological system. Basic research aiming to understand the main features of physiological evolution, along with our current knowledge, allow us to apply this approach to the analysis of both physiological and informational systems in their complexity, and to formulate some general principles. As we have shown earlier, both linguistic and biological data provide evidence for an increase in the number of regulatory factors and regulated parameters, and this increase contributes to effective conveying of information.

The paper should be taken as an attempt to analyse the principles of evolution of these systems from a novel, unconventional point of view. It has been shown above that close analogies can be drawn between the processes of evolution in physiological systems and those in natural language. It is all the more surprising, as the mechanisms of evolution of homeostatic systems and languages differ sharply. The analogies observed suggest that there exist some general regularities of functional systems' evolution. In physics, the parallels between mechanical, acoustic, and electrical phenomena have long been known and productively employed. It is conceivable that the same uniformity exists in the evolutionary processes of different systems.

\section{Acknowledgment}

The authors are grateful to Terrence W. Deacon for his most valuable comments and editing.

\section{References}

Allott, R. 1980. The motor theory of language origin. The Book Guild, Sussex.

Allott, R. 2001. The natural origin of language: Vision, action, language. Great Britain, Able Publishing.

Barcroft, J. 1934. Features in the architecture of physiological function. Cambridge University Press.

Bernard, C. 1878. Leçonssur les phénomènes de la vie communs aux animauxet aux végétaux. Paris, Ballliere, and Son. https://doi.org/10.5962/bhl.title.44802

Berwick, R. C. and Chomsky, N. 2015. Why only us: Language and evolution. MIT Press. https://doi.org/10.7551/mitpress/9780262034241.001.0001

Bichakjian, B. 1991. Evolutionary patterns in linguistics. John Benjamins Publishing. https://doi.org/10.1075/z. los2.16bic

Bolhuis, M. and Everaert, J.J. 2013. Birdsong, speech, and language: Exploring the evolution of mind and brain. MIT Press. https://doi.org/10.7551/mitpress/9322.001.0001

Bunak, V. 1980. Homo species: its origin and subsequent evolution. Nauka, Moscow. (In Russian)

Cartmill, E. A., Roberts, S., Lyn, H., and Cornish, H. 2014. The evolution of language: Proceedings of the 10th international conference (EVOLANG10). Hackensack, NJ, World Scientific.

Cavalli-Sforza, L. L., Piazza, A., Menozzi, P., and Mountain,J. 1988. Reconstruction of human evolution: bringing together genetic, archaeological, and linguistic data. Proceedings 
of the National Academy of Sciences USA 85(16):6002-6006. https://doi.org/10.1073/pnas.85.16.6002

Cavalli-Sforza, L. L., Cavalli-Sforza, L., Menozzi, P., and Piazza, A. 1994. The history and geography of human genes. Princeton university press.

Chernigovskaya, T. 1994. Cerebral lateralization for cognitive and linguistic abilities: Neuropsychological and cultural aspects. Studies in language origins 3. Eds J. Wind, A. Jonker. Amsterdam, John Benjamins: 56-76. https:// doi.org/10.1075/z.los3.07che

Chernigovskaya, T. 2004. Homo loquens: evolution of cerebral functions and language. Journal of Evolutionary Biochemistry and Physiology 40(5):495-503. https://doi. org/10.1007/s10893-005-0005-7

Chernigovskaya, T. 2007. The mirror brain, concepts, and language: The price of anthropogenesis. Neuroscience and Behavioral Physiology 37(3):293-302. https://doi. org/10.1007/s11055-007-0014-7

Chernigovskaya, T. 2013. Cheshire Grin of Schrödinger's Cat: Language and Mind. Moscow, LSK. (In Russian)

Chomsky, N. 2002. New horizons in the study of language and mind. Cambridge University Press.

Chomsky, N. and McGilvray, J. 2012. The science of language: Interviews with James McGilvray. Cambridge University Press. https://doi.org/10.1017/CBO9781139061018

Dahl, Ö. 2009. Two pathways of grammatical evolution. Syntactic complexity: Diachrony, acquisition, neuro-cognition, evolution 85:239-248. https://doi.org/10.1075/tsl.85.10two

Darwin, C. 1872. On the origin of species by means of natural selection; or, The preservation of favored races in the struggle for life. 5th ed. New York,: D. Appleton and Company. https://doi.org/10.5962/bhl.title.2106

Deacon, T. 2003. Multilevel selection in a complex adaptive system: the problem of language origins. Evolution and learning: The Baldwin effect reconsidered. MIT Press: 81-106.

Deacon, T. 2004. Monkey homologues of language areas: computing the ambiguities. Trends in Cognitive Sciences 8(7):288-290. https://doi.org/10.1016/j.tics.2004.05.006

Deacon, T. 2013. Incomplete nature: How mind emerged from matter. WW Norton \& Company.

Delson, F., Tattersall, I., and Van Coveringy. 1991. Paleoanthropology annuals. Gazland Publ. Inc., New York.

Donald, M. 1993. Precis of Origins of the modern mind: Three stages in the evolution of culture and cognition. Behavioral and Brain Sciences 16(4):737-748. https://doi. org/10.1017/S0140525X00032647

Dubina, M. V., Vyazmin, S. Y., Boitsov, V. M., Nikolaev, E. N., Popov, I. A., Kononikhin, A.S., Eliseev, I. E., and Natochin, Y. V. 2013. Potassium ions are more effective than sodium ions in salt induced peptide formation. Origins of Life and Evolution of Biospheres 43(2):109-117. https:// doi.org/10.1007/s11084-013-9326-5

Dubrovskii, V. G., Sibirev, N. V., Eliseev, I. E. Vyazmin, S. Y., Boitsov, V. M., Natochin, Y. V., and Dubina, M. V. 2013. Rate equation approach to understanding the ion-catalysed formation of peptides. The Journal of Chemical Physics 138(24):244906. https://doi.org/10.1063/1.4811280

Falk, D. 1987. Hominid paleoneurology. Annual Review of Anthropology 16(1):13-28. https://doi.org/10.1146/annurev.an.16.100187.000305

Fitch, W. T. 2000. The evolution of speech: a comparative review. Trends in Cognitive Sciences 4(7):258-267. https:// doi.org/10.1016/S1364-6613(00)01494-7

Friederici, A.D. 2011. The brain basis of language processing: from structure to function. Physiological reviews 91(4):1357-1392. https://doi.org/10.1152/physrev.00006.2011
Friederici, A. D. 2017. Language in our brain: The origins of a uniquely human capacity. MIT Press. https://doi. org/10.7551/mitpress/11173.001.0001

Galimov, E., Ryzhenko, B., and Cherkasova, E. 2011. Estimation of the composition of the Earth's primary aqueous phase. 2. Synthesis from the mantle and igneous rock material. Comparison with synthesis from the carbonaceous chondrite material. Geochemistry International 49(11):10571071. https://doi.org/10.1134/S0016702911110036

Galimov, E., Natochin, Y. V., Ryzhenko, B., and Cherkasova, E. 2012. Chemical composition of the primary aqueous phase of the Earth and origin of life. Geochemistry International 50(13):1048-1068. https://doi.org/10.1134/ S0016702912130034

Gamkrelidze, T.V. and Ivanov, V.V. 1995. Indo-European and the Indo-Europeans: A reconstruction and historical analysis of a proto-language and proto-culture. Part I: The Text. Part II: Bibliography, Indexes. Translation of Johanna Nichols. Mouton de Gruyter. https://doi. org/10.2753/RSH1061-19832201027

Givón, T. 2009. The genesis of syntactic complexity: Diachrony, ontogeny, neuro-cognition, evolution. John Benjamins Publishing. https://doi.org/10.1075/z.146

Givón, T. and Malle, B. F. 2002. The evolution of language out of pre-language. Vol.53: John Benjamins Publishing. https://doi.org/10.1075/tsl.53

Gor, K. and Chernigovskaya, T. 2004. Formal instruction and the acquisition of verbal morphology. Investigations in instructed second language acquisition. De Gruyter Mouton: 103-139. https://doi.org/10.1515/9783110197372.1.131

Haeckel, E. 1874. Anthropogenie oder entwickelungsgeschichte des menschen: Wilhelm Engelmann.

Hauser, M. D., Chomsky, N., and Fitch, W. T. 2002. The faculty of language: what is it, who has it, and how did it evolve? Science 298(5598):1569-1579. https://doi.org/10.1126/ science.298.5598.1569

Humbolt, W. von. 1836. The Heterogeneity of Language and its Influence on the Intellectual Development of Mankind (orig. Über die Verschiedenheit des menschlichen Sprachbaus und seinen Einfluss auf die geistige Entwicklung des Menschengeschlechts).

Jackendoff, R. 2003-2004. Précis of foundations of language: Brain, meaning, grammar, evolution. Behavioral and Brain Sciences 26(6):651-665. https://doi.org/10.1017/ S0140525X03000153

Jakobson, R. 1966. Implications of Language Universals for Linguistics. In Uni-versals of Language, edited by Joseph Greenberg. Cambridge, Massachusetts: MIT Press.

Jespersen, O. 1964. Language: Its nature, development and origin: (12. impr.). George Allen \& Unwin.

Kireev, M., Slioussar, N., Korotkov, A. D., Chernigovskaya, T. V., and Medvedev, S. V. 2015. Changes in functional connectivity within the fronto-temporal brain network induced by regular and irregular Russian verb production. Frontiers in Human Neuroscience 9:36. https://doi. org/10.3389/fnhum.2015.00036

Lehrer, J. 2007. Proust was a neuroscientist. $\mathrm{HMH}$.

Lieberman, P. 2013. Synapses, language, and being human. Science 342(6161):944-945. https://doi.org/10.1126/ science. 1247515

Lucas, K. 1909. The evolution of animal function. Science Progress in the Twentieth Century (1906-1916) 3(11):472-483.

Mayr, E. 1976. The Emergence of Evolutionary Novelties. Evolution and the Diversity of Life. Cambridge, MA, Harvard University Press.

Mulkidjanian, A.Y., Bychkov, A.Y., Dibrova, D. V., Galperin, M. Y., and Koonin, E. V. 2012. Origin of first cells at terrestrial, anoxic geothermal fields. Proceedings of 
the National Academy of Sciences USA 109(14):E821-E830. https://doi.org/10.1073/pnas.1117774109

Natochin, Y. 1987. Functional evolution: sources and problems. Journal of Evolutionary Biochemistry and Physiology 23(3):280-294.

Natochin, Y. V. 2005. The role of sodium ions as a stimulus for the evolution of cells and multicellular animals. Paleontological Journal 39(4):358-363.

Natochin, Y. V. 2009. The evolution of evolutionary physiology. Neuroscience and Behavioral Physiology 39(7):709716. https://doi.org/10.1007/s11055-009-9177-8

Natochin, Y. V. 2010. The origin of membranes. Paleontological Journal 44(7):860-869. https://doi.org/10.1134/ S0031030110070142

Natochin, Y. V. 2012. From quantum to integrative physiology. Neuroscience and Behavioral Physiology 42(3):271-284. https://doi.org/10.1007/s11055-012-9563-5

Natochin, Y. V. and Braunlich, H. 1991. Application of methods of toxicology in studies on the problem of evolution of renal function. Journal of Evolutionary Biochemistry and Physiology 27:584-589.

Natochin, Y.V. and Chernigovskaya, T. 1997. Evolutionary physiology: history, principles. Comparative Biochemistry and Physiology Part A: Physiology 118(1):63-79. https:// doi.org/10.1016/S0300-9629(96)00442-2

Noble, D. and Boyd, C. 1993. The challenge of integrative physiology. The Logic of Life. Oxford, New York: Oxford University Press.

Orbeli, L. 1941. Problems of evolutionary physiology. Arkhiv Biologicheskikh Nauk 61(1):43-55. (In Russian)

Pinker, S. 1994. The language instinct: How the mind creates language. Penguin, UK.

Pribram, K. H. 2013. The form within: My point of view. Easton Studio Press, LLC.

Ragir, S. 1992. Adaptationist and nativist positions on language origins: a critique; 39-48 in: Language origin: a multidisciplinary approach: Springer. https://doi. org/10.1007/978-94-017-2039-7_3

Read, D. W. 2008. Working memory: A cognitive limit to nonhuman primate recursive thinking prior to hominid evolution. Evolutionary Psychology 6(4):147470490800600413. https://doi.org/10.1177/147470490800600413

Sapir, E. 1921. Language: An introduction to the study of speech: Harcourt Brace and World, New York.

Saussure, F. 1916. Le cours de linguistique générale. Payot, Paris.

Schleicher, A. 1873. Die Darwinsche Theorie und die Sprachwissenschaft: offenes Sendschreiben an Herrn Dr. Ernst Häckel, o. Professor der Zoologie und Direktor des zoologischen Museums an der Universität Jena: Böhlau.

Schmalhausen, I. I. 1949. Factors of evolution: the theory of stabilizing selection. (In Russian)

Severtsov, A. N. 1914. Current problems in evolutionary theory. Nauka. Moscow. (In Russian)

Sia, G.-M., Clem, R., and Huganir, R. L. 2013. The human language-associated gene SRPX2 regulates synapse formation and vocalization in mice. Science 342(6161):987-991. https://doi.org/10.1126/science.1245079

Slioussar, N., Kireev, M.V., Chernigovskaya, T.V., Kataeva, G. V., Korotkov, A. D., and Medvedev, S. V. 2014. An ER-fMRI study of Russian inflectional morphology. Brain and Language 130:33-41. https://doi.org/10.1016/j. bandl.2014.01.006

Smith, H. W. 1953. From fish to philosopher. The story of our internal environment. Boston: Little, Brown \& Co.

Wallace, R. 1994. Spatial mapping and the origin of language. Studies in Language origins 3:31-44. https://doi. org/10.1075/z.los3.05wal

Wind, J., Chiarelli, B., Bichakjian, B., Nocentini, A., and Jonker, A. 1992. Language origin: A multidisciplinary approach: NATO ASI Series. Kluwer Acad. Publ., Dordrecht, Boston. https://doi.org/10.1007/978-94-017-2039-7 